\title{
Como Melhorar a Comunicação e Prevenir Conflitos nas Situações de Terminalidade na Unidade de Terapia Intensiva*
}

\author{
How to Improve the Communication and to Prevent the Conflicts at \\ Terminality Situations in Intensive Care Unit
}

Rachel Duarte Moritz'

\section{RESUMO}

JUSTIFICATIVA E OBJETIVOS: A angústia diante do morrer e o maior tempo de permanência dos pacientes críticos nas unidades de terapia intensiva (UTI) são fatores que têm levado a necessidade da melhoria da comunicação entre todos os envolvidos no tratamento desses enfermos, o que justifica esse trabalho, que visa a abordagem desse tema.

CONTEÚDO: Foi utilizada a experiência da autora e foram revisados, através da MedLine, do UptoDate, do Google e da Revista Brasileira de Terapia Intensiva, os artigos escritos, nos últimos cinco anos, abordando os temas morte, comunicação, UTI.

CONCLUSÕES: A adequada comunicação entre o médico, o paciente, seus familiares e a equipe multiprofissional da UTI é um dos principais fatores que interferem na satisfação, tanto dos pacientes quanto daqueles que trabalham nessa unidade. Para a adequada informação o médico intensivista deve ter a consciência dos seus limites terapêuticos curativos e deve aprender a tratar do paciente durante o processo do morrer. Dessa forma sentir-se-á seguro para falar sobre a morte. Seria ideal que o profissional responsável por fornecer a notícias fosse experiente, tanto do ponto

1. Professora de Medicina de Urgência da Universidade Federal de Santa Catarina (UFSC); Mestre em Ciências Médicas; Doutora em Engenharia de Produção - Ergonomia

*Recebido da Medicina de Urgência da Universidade Federal de Santa Catarina (UFSC), Florianópolis, SC

Apresentado em 13 de outubro de 2007

Aceito para publicação em 26 de novembro de 2007

Endereço para correspondência:

Dra. Rachel Duarte Moritz

Rua João Paulo 1929

88030-300 Florianópolis, SC

E-mail: rachel@hu.ufsc.br

(C)Associação de Medicina Intensiva Brasileira, 2007 de vista técnico quanto ético e que fosse, sempre que possível, o mesmo emissor. O principal envolvido no processo do morrer, pouco poderá influir. Entretanto, caso haja possibilidade de comunicação essa deverá ser realizada de forma simples, honesta e humana. A família do paciente tem o direito de estar ao lado daquele que ama e de ser informada, com constância, sobre a verdade do seu quadro clínico. Todos os atores do processo devem saber a verdade e as linhas terapêuticas escolhidas. A comunicação, idealmente, será efetuada em ambientes tranqüilos e reservados.

Unitermos: comunicação, morte, UTI

\section{SUMMARY}

BACKGROUND AND OBJECTIVES: The suffering with the death and the prolonged time of patient's admission in a intensive care unit (ICU) are factors that leads to necessity the best communication with the personal that works in ICU, patients and their family, and its justify this work, whose objective is discuss this subject.

CONTENTS: The professional experience of the author was used in this issue and the articles written during the last five years about death, communication and ICU were reviewed by means of MedLine, Up to Date, Google and Brazilian Journal of Intensive Therapy.

CONCLUSIONS: It was concluded that the physician, the patient together with her/his family, and the multiprofessional staff of the ICU is one of the main factors that interferes with the process of satisfying both the patient and the ones who work on such unities. For adequate information, the physician must be conscious about therapeutic limits, and must learn how to treat the patient during the process of dying. In this way, the physician will be apt to talk about death. The ideal situation would be that the professional, responsible to give the news, should be experience, from the technical point of view as well as ethical, and should be the same person, as always as possible, when neces- 
sary. The patient mostly little be able to influence in her/ his process of dying, but if communication is possible, it be simple, honest and humane. The patient's family members have the right of being together with the one who they love, and of being steadily informed about the real situation. All the members in the process must know the truth and the chosen therapeutic orientation to be taken. Communication should be done in a quiet and prived place.

Key Words: communication, death, ICU

\section{INTRODUÇÃO}

O aperfeiçoamento tecnológico tem permitido uma modificação gradual da dinâmica operacional nas unidades de terapia intensiva (UTI). Pode-se citar como principais conseqüências dessa mudança, a necessidade da tomada de decisões diante da morte e do morrer e o maior tempo de permanência dos pacientes críticos nessas unidades. Esses fatos têm levado a constatação da importância de que haja uma harmonia entre os profissionais que trabalham nas UTI, os pacientes internados nessas unidades e os seus familiares. Portanto, torna-se necessário que haja uma busca pela melhoria do relacionamento entre os atores envolvidos no processo do tratamento do paciente crítico.

\section{MÉTODO}

Para a abordagem do assunto foi utilizada primordialmente a experiência profissional da autora. A revisão bibliográfica foi efetuada através da busca de palavraschave: morte, comunicação e UTI, no Google, e Death, Intensive Care Unit and comunication na MedLine. Foram revistos os artigos citados que abordaram o tema na área de Bioética, para adultos, nos últimos cinco anos. Esses artigos foram também pesquisados no Up to Date e na Revista Brasileira de Terapia Intensiva, no mesmo tempo e com as mesmas palavras-chave descritas.

A comunicação está diretamente ligada aos sentidos humanos. Portanto, torna-se impossível para o homem não se comunicar e viver isolado, a margem da sociedade. Os componentes da comunicação são: o emissor, o receptor, a mensagem, o canal de propagação, o meio de comunicação, a resposta e o ambiente onde o processo comunicativo se realiza ${ }^{1}$.

Nas UTI o principal emissor da comunicação sobre o paciente gravemente enfermo é o médico intensivista. Esse profissional tem o dever de transmitir a situação da doença ao paciente, aos seus familiares, aos seus amigos e ao seu médico assistente. Deve também informar os pormenores do tratamento aos membros da equipe multiprofissional que trabalham no setor. Obviamente esses profissionais interferem e interagem na comunicação dentro da UTI². Entretanto, não pode ser esquecido que a responsabilidade final do tratamento de um paciente é do médico e que esse profissional jamais poderá se eximir da sua participação prioritária na comunicação. A mensagem a ser transmitida abrange invariavelmente pormenores do quadro clínico e do prognóstico do paciente. O canal de propagação é geralmente verbal, face-a-face, nas salas de espera da UTI. Essa é uma forma simplista de abordar um tema tão complexo.

A comunicação nas situações de terminalidade tornase complexa por influência de inúmeros fatores que interferem nos agentes envolvidos.

A dificuldade da comunicação durante o processo do morrer tem fundamentos históricos. Merece destaque o fato de que só se consegue a comunicação adequada quando se tem conhecimento e tranqüilidade para abordar determinado tema.

"Esta vida é uma estranha hospedaria, de onde se parte quase sempre às tontas, pois nunca as nossas malas estão prontas e a nossa conta nunca está em dia"

As palavras do poeta Mário Quintana, citadas, mostram o quanto é difícil o ser humano aceitar e conseqüentemente falar sobre a morte. Para os médicos, formados para tratar e curar, a morte dos seus pacientes pode significar o seu erro ou fracasso. Portanto, falar sobre a morte pode tornar-se um calvário para esses profissionais, o que conseqüentemente será um empecilho na sua comunicação. Outro fato importante a ser ressaltado é o relacionamento da equipe multiprofissional. Se todos os profissionais envolvidos com o tratamento durante o processo de morrer não se sentirem seguros para o enfrentamento da morte e, se não houver clareza entre todos os membros da equipe, haverá, sem sombra de dúvidas, um conflito de interesses que irá culminar em problemas de relacionamento e de comunicação ${ }^{3,4}$.

Kübler-Hoss ${ }^{5}$, uma profissional que dedicou toda a vida para o tratamento e o melhor entendimento do processo de morrer, da sua experiência e dedicação com os pacientes conhecedores da evolução letal de suas doenças conseguiu categorizar cinco estágios pelos quais passam os enfermos diante da aproximação da morte. Primeiro a negação e o isolamento. A vontade de que a proximidade do êxito letal não seja verdadeira constrói sua negação e justifica a busca de fatos para alicerçá- 
la. A negação funciona como defesa. A ansiedade gerada é proporcional à falta de preparo, por parte do médico, para a revelação do diagnóstico. Segundo, a indignação. A raiva contra tudo, contra todos, inclusive a revolta contra Deus. Por que eu? O paciente passa a apresentar um comportamento agressivo contra aqueles que o rodeiam, tanto seus médicos quanto seus amigos e familiares. Essas agressões jamais devem ser admitidas como pessoais. Terceiro, a barganha. $\mathrm{O}$ desejo de ser recompensado por boas ações. Essa fase é curta, as vezes imperceptível, mas igualmente importante para o paciente. Quarto, a depressão, a revolta, a raiva cedem lugar a um profundo sentimento de perda. Nesse estágio as palavras pouco valem. O sentar-se ao lado em silêncio compartilha o sofrimento e inspira afeto. Finalmente, o quinto e último estágio: a aceitação, que não deve ser confundida com o sentimento de felicidade. Às vésperas da morte, o paciente pode encontrar paz. Fica mais em silêncio, o círculo de interesses diminui, o paciente sabe que vai morrer e não se desespera. A partir dessas definições pode ser questionado se todas essas etapas não serão também vividas pelos familiares e pelos profissionais de saúde que cuidam do paciente. Cabe então ao médico, nesse momento, saber interpretar em que fase encontram-se os envolvidos no processo e saber a melhor comunicação para cada momento distinto. Rubem Alves ${ }^{6}$, escrevendo sobre a morte, descreveu os sentimentos de uma senhora à beira da morte, dos quais ressalta-se:

"Doutor; Será que escapo desta? Mas por favor, não responda: Estamos fazendo tudo o que é possivel para que você viva. Olhe, sou uma mulher inteligente. Os sinais são claros. Sei que vou morrer. O que desejo é que me ajude a morrer. Morrer é difícil. E ficarei feliz se me disser, olhando nos meus olhos: Você está com medo de morrer. Eu também tenho medo de morrer".

Esse texto mostra o quanto é importante para o médico perder os seus medos sabendo chegar perto e entendendo as necessidades reais dos pacientes sob seus cuidados. Não se pode deixar de mencionar a importância do reconhecimento das diferenças sócioculturais que influem enormemente no entendimento do morrer e na comunicação sobre esse tema ${ }^{7-11}$.

Um estudo norte-americano ${ }^{12}$ que avaliou a freqüência da comunicação dos médicos com os familiares de 70 pacientes críticos, mostrou que essas pessoas mostraram-se satisfeitas com a informação prestada, embora, $19 \%$ fossem inábeis para entender todo o seu conteúdo. Os autores concluíram que a adequada comunicação influi positivamente na satisfação pelos serviços prestados. Outro estudo ${ }^{13}$ que avaliou 256 questionários respondidos por familiares de paciente críticos demonstrou que a maioria daqueles que participaram do estudo considerou que a adequada comunicação, a tomada de decisão correta, o respeito e a compaixão para com o paciente e seus familiares são a chave determinante da satisfação familiar.

Uma realidade distinta nas UTI é que o médico intensivista muitas vezes exerce sua função como plantonista. Esse fato coloca-o mais distante do paciente, não criando laços afetivos com ele e com seus familiares. Nessas unidades, a monitoração moderna permite o reconhecimento de todos os elementos que influenciam no quadro clínico do paciente. Esse fato gera um sentimento de obrigação do médico intensivista explicar e qualificar a morte do enfermo à família e a si mesmo. Nestas circunstâncias, comunicar à família o óbito do paciente pode se tornar uma difícil obrigação, uma vez que a falta de profundidade na relação do médico com o paciente internado na UTI e, conseqüentemente, com os seus entes queridos, deixa-o mais frágil para entrar em contato direto com o símbolo do seu "fracasso", a morte ${ }^{14}$. Walllau e col. ${ }^{15} \mathrm{com}$ o objetivo de avaliarem a visão dos familiares sobre a qualidade e humanização do atendimento em Medicina Intensiva, entrevistaram 100 familiares de pacientes internados na UTI por mais de 48 horas. Os autores constataram que a comunicação surgiu como o principal fator apontado para a qualidade insatisfatória no serviço. Quinze por cento dos entrevistados declararam-se insatisfeitos com as informações médicas prestadas e 5\%, apesar de afirmar satisfação, reclamaram por ter que conversar com diferentes médicos cada dia.

Falar sobre o real prognóstico do paciente, informar claramente sobre a evolução da sua doença sem esquecer o envolvimento emocional que cerca o morrer, deve fazer parte de um processo contínuo de comunicação entre todos os integrantes desse processo ${ }^{15}$. Torna-se importante relembrar que não basta ao médico tentar melhorar a comunicação no momento da morte do seu paciente, pois a relação médico-paciente é embasada na adequada comunicação desde o primeiro contato. Ray e Johnson ${ }^{16}$ realizaram um estudo descritivo e não intervencionista que avaliou 165 pacientes que morreram na UTI (65\% das mortes no hospital). Os autores constataram que os pacientes que morreram na UTI não haviam sido informados sobre a possibilidade da escolha entre cuidados paliativos e tratamento intensivo. A falta de experiência profissional dos médicos, principalmente no que concerne ao manuseio com 
aqueles que estão morrendo, influiu na admissão dos pacientes com prognóstico reservado na UTI. Esse fato é relevante pois, cada vez mais, o médico intensivista deve discutir a otimização da utilização dos leitos da UTI. Para essa discussão é essencial a formação e a experiência desse especialista.

Não existem controvérsias quanto à importância da adequada comunicação entre o médico e seu paciente, mesmo que este esteja internado em UTI. Entretanto, nessas unidades, o paciente quase que invariavelmente é sedoanalgesiado e os fármacos administrados interferem sobremaneira na comunicação desse paciente. Portanto, na maioria dos casos, a comunicação é realizada com os familiares e amigos dos pacientes. Deve-se lembrar que, antes de falar com o enfermo crítico, o médico deve certificar-se da sua capacidade de comunicação ${ }^{17}$. Deve-se levar em consideração que esses enfermos, quando possuem a capacidade de comunicação, não desejam aulas de Medicina crítica e sim informação individualizada sobre o seu quadro clínico e as perspectivas de tratamento ${ }^{18-20}$. É importante mencionar que os familiares daquele que está morrendo, ao serem confrontadas com a perda do seu ente querido, podem fugir da realidade ou podem querer encontrar um culpado para redimir o seu sentimento de culpa. Esse é outro fator complicador da adequada comunicação sobre a morte e o morrer.

Os ambientes de UTI geralmente são frios e distantes da vida. A dinâmica operacional desses setores afasta ainda mais aqueles que estão visitando o paciente gravemente enfermo. Levando em consideração a importância da privacidade do enfermo que está morrendo e da sua proximidade com seus familiares, Fridh e col. ${ }^{21}$ enviaram um questionário a 192 familiares de pacientes que haviam morrido. Os autores constataram que $40 \%$ das mortes ocorreram sem os familiares estarem presentes e que em $46 \%$ dos casos os quartos eram compartilhados. Aqueles que tinham seus entes queridos perto necessitaram menos sedação e analgesia. Foi sugerido que os ambientes de UTI devem ser modificados para promoverem melhor atendimento no fim da vida dos seus pacientes.

Adiciona-se a essa realidade a rotina da informação, que geralmente ocorre, de forma impessoal, numa sala de espera ou pior ainda, nos corredores que antecedem a UTI. Nesse momento, a mensagem a ser passada nem sempre é otimista e muitas vezes é pouco compreendida pois é fornecida através de palavras técnicas, longe da realidade daquele que está ouvindo.
É tradição na área médica que os atos performáticos sejam valorizados e que a comunicação seja considerada secundária e, por esse motivo, delegada para os profissionais mais inexperientes. Nesse momento o médico parece esquecer que a adequada comunicação é o principal fator para a satisfação dos pacientes e de seus familiares, quanto ao atendimento prestado ${ }^{15}$. Fugindo de falar e de sentir, junto com os familiares, a dor da perda, o médico distancia-se daqueles que tanto dele necessitam.

Diante do exposto, a autora permite-se concluir que a adequada comunicação entre o médico, o paciente, seus familiares e a equipe multiprofissional da UTI é um dos principais fatores que interferem na satisfação, tanto dos usuários quanto daqueles que trabalham nessas unidades. Para que haja comunicação eficaz torna-se necessário o seguimento de diversos aspectos. O médico intensivista deve ter a consciência dos seus limites terapêuticos curativos e deve aprender a tratar do paciente durante o processo do morrer. Dessa forma sentir-se-á seguro para falar sobre a morte com os envolvidos no processo. Seria ideal que o profissional responsável por fornecer as notícias fosse experiente, tanto do ponto de vista técnico quanto ético e que fosse, sempre que possível, o mesmo emissor. O principal envolvido no processo do morrer, pouco poderá influir. Entretanto, caso haja possibilidade de comunicação essa deverá ser realizada de forma simples, honesta e humana. Os familiares do paciente têm o direito de estar ao lado daquele que amam e de serem informados, com constância, sobre a verdade do seu quadro clínico. Todos os atores do processo devem saber a verdade e as linhas terapêuticas escolhidas. A comunicação deverá ser em ambiente tranqüilo e reservado, devendo-se levar em consideração que cada indivíduo tem o seu momento para o adequado entendimento.

\section{REFERÊNCIAS}

01. Wikipédia, a enciclopédia livre. Comunicação http://pt.wikipedia.org (pesquisado em agosto -2007).

02. Ho KM, English S, Bell J - The involvement of intensive care nurses in end-of-life decisions: a nationwide survey. Intensive Care Med, 2005;31:668-673.

03. Moritz RD - A Morte e o Morrer nas Unidades de Terapia Intensiva, em: David CM - Medicina Intensiva. $1^{\mathrm{a}} \mathrm{Ed}$, Rio de Janeiro, Revinter, 2005;68-78.

04. Moritz RD - Os profissionais de saúde diante da morte e do morrer. Bioética, 2005;13:51-63.

05. Kübler-Hoss E - Sobre a Morte e o Morrer. $8^{a}$ Ed, São Paulo: Martins Fontes, 1998;296.

06. Alves R - Sobre a Morte. Bioética, 2005;13 33-35.

07. Ganz FD, Benbenishty J, Hersch M et al - The impact of regional culture 
on intensive care end of life decision making: an Israeli perspective from the ETHICUS study. J Med Ethics, 2006;32:196-199.

08. Van Oorschot B, Simon A - Importance of the advance directive and the beginning of the dying process from the point of view of German doctors and judges dealing with guardianship matters: results of an empirical survey. J Med Ethics, 2006;32:623-626.

09. Gherardi C, Chaves M, Capdevila A et al - Death in an intensive care unit. Influence of life support withholding and withdrawal. Medicina (B.Aires), 2006;66:237-241.

10. Wunsch H, Harrison DA, Harvey $\mathrm{S}$ et al - End-of-life decisions: cohort study of the withdrawal of all active treatment in intensive care units in the United Kingdom. Intensive Care Med, 2005;31:823-831.

11. Moritz RD, Pamplona F - Avaliação da recusa ou suspensão de tratamentos considerados fúteis ou inúteis em UTI. Rev Bras Terap Intens, 2003;15:40-44.

12. LeCalire MM, Oakes JM, Weinert CR - Communication of prognostic information for critically ill patients. Chest, 2005;128:1728-1735.

13. Heyland DK, Rocker GM, O'Callaghan CJ et al - Dying in the ICU: perspectives of family members. Chest, 2003;124:392-397.
14. Aleluia I - O medico e a morte na UTI. www.hsf.org.br/ (pesquisado em agosto de 2007).

15. Wallau RA, Guimarães HP, Falcão LFR et al - Qualidade e humanização do atendimento em Medicina Intensiva. Qual a visão dos familiares? Rev Bras Terap Intens, 2006;18:45-51.

16. Moritz RD - Sobre a morte e o morrer. Rev Bras Terap Intens, 2005; $17: 5-6$

17. Rady MY, Johnson DJ - Admission to intensive care unit at the end-oflife: is it an informed decision? Palliat Med, 2004;18:705-711.

18. Gillick M - Ethical issues near the end of life. UpToDate:April 11, 2006 (pesquisado em agosto de 2007).

19. Kellum JA, Dacey MJ - Ethics in the intensive care unit: informed consent withholding and withdrawal of life support; and requests for futile therapies - UpToDate: August 18, 2006 (pesquisado em agosto de 2007).

20. Chaitin E, Arnold RM - Communication in the ICU: Holding a family meeting. UpToDate: May 11, 2007 (pesquisado em agosto de 2007).

21. Fridh I, Forsberg A, Bergbom I - Family presence and environmental factors at the time of a patient's death in an ICU. Acta Anaesthesiol Scand, 2007;51:395-401. 